\title{
A physical-biogeochemical coupling scheme for modeling marine coastal ecosystems
}

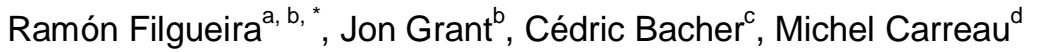

a Consejo Superior de Investigaciones Científicas (CSIC), Instituto de Investigaciones Marinas, c/Eduardo Cabello 6, 36208 Vigo, Spain

${ }^{\mathrm{b}}$ Department of Oceanography, Dalhousie University, Halifax, Canada NS B3H 4J1

${ }^{\mathrm{c}}$ French Institute for Sea Research (IFREMER), BP70, 29280 Plouzané, France

${ }^{d}$ Hatch Ltd, 5 Place Ville Marie Suite 200, Montréal, Québec, Canada H3B 2G2

*Corresponding author : Ramón Filgueira, email address : ramonf@iim.csic.es

\begin{abstract}
:
Ecological modeling of dynamic systems such as marine environments may require detailed spatial resolution when the modeled area is greatly influenced by complex physical circulation. Therefore, the simulation of a marine ecosystem must be underlain by a physical model. However, coupling hydrodynamic and biogeochemical models is not straightforward. This paper presents a modeling technique that can be used to build generic and flexible fully-spatial physical-biogeochemical models to study coastal marine ecosystems using a visual modeling environment (VME). The model core is constructed in Simile, a VME that has the capacity to create multiple instances of submodels that can be interconnected, producing a fully-spatial simulation. The core is designed to assimilate a choice of different hydrodynamic models by means of matrices, enhancing its compatibility with different software. The biogeochemical model can be modified by means of a graphical interface, which facilitates sharing within the scientific community. This paper demonstrates the application of the coupling scheme to mussel aquaculture in Tracadie Bay (PEI, Eastern Canada). The model was run for two different years, 1998 and 1999, and indicated that mussel biomass exerts a top-down control of phytoplankton populations, causing a maximum chlorophyll depletion of $61.0 \%$ and $80.3 \%$ for 1998 and 1999 respectively. The difference between both years highlights the importance of inter-annual variability, which is significant from an ecosystem-level perspective because it reveals the relevance of applying a precautionary policy in the management of aquaculture activity. Therefore, the proposed core developed in Simile is a generic and flexible tool for modeling long-term processes in coastal waters, which is able to assimilate a choice of hydrodynamic models, constituting a novel approach for generating fully-spatial models using visual modeling environments.
\end{abstract}

\section{Highlights}

An offline physical-biogeochemical coupling scheme for marine systems is presented. The scheme can be used as a generic core to create fully-spatial models. The biogeochemical model can be easily modified using the Simile's GUI. Its application is demonstrated in an aquaculture site in PEI (Eastern Canada).

Keywords: Physical-biogeochemical coupling; Marine spatial planning; Aquaculture; Simile 


\section{Introduction}

Dynamic ecosystem models provide a powerful approach to predict the consequences of natural or anthropogenic changes related to pollution, climate change, land-use patterns and other impacts. Models of marine ecosystems contain many examples of successful application of this approach, including nutrients cycles, contaminant dispersion, eutrophication and aquaculture-ecosystem interactions (e.g., Sarmiento et al., 1993; Chapelle et al., 1994; Baretta et al., 1995; Allen et al., 2010; Filgueira and Grant, 2009; Grant and Filgueira, in press). Ecosystem models have been used in the field of shellfish aquaculture to evaluate how the energy flow toward cultured biomass may potentially alter the food supply for other trophic levels such as natural benthos (Cloern, 1982; Dowd, 2003). In addition, ecological modelling is valuable in the study of bivalve growth and/or culture carrying capacity (Bacher et al., 1998; Dowd, 1997; Duarte et al., 2003; Ferreira et al., 1998; Grant et al., 2007a; Pastres et al., 2001; Raillard and Menesguen, 1994) and the effects of aquaculture on the ecosystem (Chapelle et al., 2000; Dowd, 2005). Carrying capacity models have been applied to manage cultivation areas (Bacher et al., 1998; Duarte et al., 2003; Ferreira et al., 1998) or increase profit in new areas (Heral, 1993). Given that coastal ecosystems are influenced largely by hydrodynamics, dynamic fully-spatial models must be underlain by a hydrodynamic model including the influence of diffusion-advection forced by tides, winds, and density gradients.

58 Circulation is the spatial manifestation of these processes and division of the environment

59 into grid cells (e.g. finite element grid) allows these flows to be spatially resolved. The grid cells are not only connected, but they are conservative with respect to water flux, requiring a 
61 hydrodynamic model based on equations of water motion. Although the models can be

62 simplified, as in tidal prism calculations, spatial resolution is also sacrificed. There are many

63 examples in which a hydrodynamic model is integrated with ecosystem fluxes to create

64 spatial simulations (e.g. Ferreira et al., 2008; North et al., 2010), but this integration is not

65 straightforward. For example, visual modelling environment (VME) software such as Stella

66 (http://www.iseesystems.com) allows users to create models without writing code

67 (Muetzelfeldt and Massheder, 2003). This has many advantages such as increased availability

68 of simulation tools to non-specialists (i.e. researchers without in-depth knowledge of

69 informatics/code programming), sharing of models between users, and efficient re-use of

70 submodels (Silvert, 1993). Despite the sophistication of some VMEs, the ability to

71 incorporate spatial realism as well as hydrodynamics has been limited and according to our

72 knowledge there are no studies in the literature in which VMEs were used to generate

73 detailed spatial resolution models of dynamic systems such as marine environments. VMEs

74 have been more successfully applied to terrestrial environments (e.g. Elshorbagy et al., 2006;

75 Randhir and Tsvetkova, 2011) in which physical processes such as groundwater flow can be

76 simplified relatively easily compared to coastal hydrodynamics. For marine environments,

77 improved ability to easily construct coupled physical-biogeochemical fully-spatial models

78 based on VME would be beneficial, because it is a natural extension of the spatial context

79 fostered by GIS, marine spatial planning and ecosystem-based management.

80

81 In addition, although the examples cited above are well-developed marine ecosystem models,

82 the methodology is not easily adapted to other locations. Our focus in this paper is to provide

83 insight about the integration of biogeochemical and ecological data with circulation models

84 using object-oriented software, and to deliver a generic and flexible coupling environment 
where the effort to export the model to other locations is reduced. The coupling scheme is developed in Simile (Appendix A), which is well suited to spatial models because it allows 'multiple instances' of a given submodel that can be interconnected, creating spatial connections (Muetzelfeldt and Massheder, 2003). In this study we demonstrate the application of the coupling scheme with an example from an aquaculture site in Prince Edward Island (Eastern Canada). In this example we used AquaDyn to create the hydrodynamic model and Matlab to calculate and deliver water exchange coefficients into Simile. We emphasize that AquaDyn and Matlab are not specific requirements of the coupling scheme, they are the tools used in this specific example. Other hydrodynamic models such as open source FVCOM (http://fvcom.smast.umassd.edu/) can also be used, as well as the open source Octave (http://www.gnu.org/software/octave/), R (http://www.rproject.org/) or Scilab (http://www.scilab.org/) instead of Matlab (http://www.mathworks.com/).

\section{Material and Methods}

\subsection{Description of the physical-biogeochemical coupling scheme}

In detailed spatial resolution models software must keep track of spatial locations and be suited to mapping, which is not generally a feature of VME applications. Fully-spatial models require more spatial complexity than the few boxes that can easily be set up in commerciallyavailable VMEs. However, Simile is highly adaptable to handling spatial information, but there may be similar capacity in other software. Simile allows 'multiple instances' of a submodel that can represent the topology of the finite element grid created by the hydrodynamic model. These finite element grids are commonly composed by triangles or 
109 squares called elements, which are defined by nodes and links (Figure 1a). The

110 hydrodynamic model reports water velocity and direction for each node, allowing a

111 calculation of water exchange between elements, which accounts for the hydrodynamics of

112 the spatial connections. The crux of the coupling scheme is as follows (Figure 2):

- The hydrodynamic model generates a finite element grid and corresponding

114 hydrodynamic regime.

115 - Simile reads the spatial topology of the finite element grid and hydrodynamics, which

116 allow the coupling with the biogeochemical model.

117 - The biogeochemical results from Simile track the spatial topology, which can then be $118 \quad$ exported to GIS.

\subsection{Adapting hydrodynamic results to Simile}

121 The steps described in this section are common to all hydrodynamic models that can deliver

122 results organized in matrices such as AquaDyn (Appendix A) or FVCOM. The following

123 procedures (See Appendix B for a detailed description) were automated through a Matlab 124 script:

- Velocity vectors are combined as root mean square velocities across grid boundaries to calculate the water flux in each element link for each time step. It is recommended the smallest time step possible be combined with the available computational power in order to provide the best resolution to the time series.

- Water fluxes of each time step are combined to generate average volumetric water exchange for each link.

- An optimization algorithm is applied to minimize the potential residual water imbalance caused by the averaging procedure. 
- A matrix is generated with the averaged volumetric water exchange for each link.

135 We present an example using averaged hydrodynamics rather than time-dependent flows in

136 order to simplify the coupling scheme. The volumetric water exchange between elements is

137 calculated simultaneously in the whole grid following a first order upwind scheme. The water

138 exchange between two adjacent elements is not calculated as a net flow but as a dispersion

139 flow. This is a generalization of the tidal prism method at the scale of each element such that

140 for each link between two adjacent elements, two averaged flows are calculated, one going

141 from element $i$ to $j$ and one going from $j$ to $i$. These exchange coefficients are divided by the

142 volume of the elements where the flow enters in order to provide rates expressed as

143 percentage day ${ }^{-1}$

144

\subsection{Simile structure to read spatial information}

146 Simile establishes relationships between the different submodels, which represent the

147 elements of the grid, using its 'Condition' function, which specifies whether a connection

148 between submodel instances exists. The use of 'Condition' requires a specific submodel that

149 is described in Appendix C. This submodel allows reading the topology and the

150 hydrodynamics of the hydrodynamic model by means of matrices. Therefore, this submodel

151 provides a template that can be used as a core to develop any physical-biogeochemical model

152 in Simile without further altering the coupling scheme itself.

153

154 In order to verify that water exchange parameterized within Simile is consistent with the

155 physics predicted by the hydrodynamic model, a simple verification process is suggested.

156 Both Simile and the hydrodynamic model are set up in the same way to run a model in which 
157 a conservative tracer is the only component. Assuming a constant concentration of the tracer

158 at the boundary and a lower and homogeneous distribution inside the bay at time 0 , the model

159 is run until equilibrium is reached. By comparing the tracer distribution in the bay after a

160 period of time, we determine if Simile is correctly assimilating the hydrodynamics. It is very

161 important to compare the general pattern and not the high frequency events, because the

162 hydrodynamic model is using a continuous time series of water exchange and depth,

163 including tidal variation, while Simile is using averaged values. This verification procedure is

164 an internal control of the coupling process and does not exempt the researcher from

165 validation of the physical and biogeochemical model.

166

167 2.4. Exporting the results to GIS

168 Simile outputs provide a single value for each triangular element, but these triangles are 169 differently sized. Therefore, if these data were plotted in GIS, the weighting represented by 170 the area of the triangle would not be preserved. This can be corrected by calculating the 171 position of geometric reference points (Figure 1) within each triangle (Script available on 172 request) based on its geometry:

- Centroid: the point of intersection of triangle medians (the lines joining each vertex with the midpoint of the opposite side). The centroid is the center of mass of an

175 element and therefore the single value output by Simile.

176 - Nodes: the triangle's vertices calculated as the average of the centroids sharing the 177 same vertex.

178 - Midpoints between the centroid and each node: calculated as the average between the 179 centroid and the corresponding vertex. 
181 These geometric points provide a grid that accounts for the differential area of grid cells. The

182 maps we show below (Figure 4 and 10) were created with this method and plotted using

183 AquaDyn capabilities. In addition, the Cartesian coordinates used in the hydrodynamic model may be normalized to UTM and used in any GIS.

185

186

\subsection{Tracadie Bay Example}

187

\subsubsection{Study Site and objective}

188 An example of the coupling approach is presented for Tracadie Bay, Prince Edward Island,

189 Canada (Figure 3). The bay is a small $\left(16.4 \mathrm{~km}^{2}\right.$ at mean tide and $13.8 \mathrm{~km}^{2}$ at low tide),

190 shallow (maximum depth $6 \mathrm{~m}$ ) barrier beach inlet with semidiurnal tides (range of $0.6 \mathrm{~m}$ ). It

191 is open to the Gulf of Saint Lawrence through a single narrow channel. Exchange of the bay

192 with the offshore is up to $500 \mathrm{~m}^{3} \mathrm{~s}^{-1}$ (Dowd, 2003), which results in a turnover of the entire

193 volume of the Bay every 4-10 days (Dowd, 2005). Winter Harbour empties into the southeast

194 of Tracadie Bay where Winter River drains a large watershed, but the input of freshwater is

195 low for much of the year $\left(\sim 1 \mathrm{~m}^{3} \mathrm{~s}^{-1}\right.$; see also Cranford et al., 2007). Mussel culture in the bay

196 is located as shown in Figure 3 and the biomass calculated according to Dowd (2003, 2005),

197 who estimated a standing stock of between 1 and $2 \times 10^{6} \mathrm{~kg}$ wet weight mussels. The

198 standing stock of $1.5 \times 10^{6} \mathrm{~kg}$ wet weight of mussels is considered the actual scenario in

199 Tracadie Bay and it is homogeneously distributed in culture areas (Figure 3). Tissue weight

200 was calculated assuming a condition index of 30\%. Dry weight was calculated assuming

201 water content of $80 \%$ and a carbon content of $40 \%$ mussel dry weight.

202

203 The goal of this example is to analyze phytoplankton depletion due to suspension feeding contrasting two consecutive years, 1998 and 1999, with different far-field conditions, and to 
205 demonstrate the potential of the model for studying the implications of inter-annual variations

206 in carrying capacity estimations. The main purpose of this example is to show how to apply

207 the coupling scheme. Implications of the model for aquaculture environment interactions

208 have been explored in the references cited below.

209

$210 \quad$ 2.5.2. Hydrodynamic Model

211 The boundaries and depths of the bay were digitized from a hydrographic chart. The finite

212 element mesh was generated within AquaDyn, tuning mesh size and density. The 2D

213 hydrodynamics was forced by a time series of sea level, and friction was applied via a

214 Manning coefficient. The resulting triangular mesh contained 544 elements, and 1454

215 connections across links. Application of an AquaDyn model to Tracadie Bay was validated

216 using sea level data (Grant et al., 2005). In the present study, the hydrodynamic model was

217 further ground-truthed by comparing the modulus of velocity vector in Node \# 236 with

218 current meter time series available for the same location $\left(46^{\circ} 23^{\prime} 56^{\prime}\right.$ ' $\mathrm{N}, 62^{\circ} 59^{\prime} 56^{\prime}$ ' $\left.\mathrm{W}\right)$ and

219 period between 15 June and 15 September 2002.

220

$221 \quad$ 2.5.3. Biogeochemical model

222 The biogeochemical model used in Simile is based on a classical PNZ model (phytoplankton

$223(\mathrm{P})$ - Nutrients $(\mathrm{N})$ - Zooplankton $(\mathrm{Z})$ ) with the addition of mussel (M) and detritus (D)

224 submodels. Given the minimal effect of Zooplankton in the results, this submodel was turned

225 off in subsequent scenarios. All the submodels are characterized in terms of carbon per cubic

226 meter $\left(\mathrm{mg} \mathrm{C} \mathrm{m}^{-3}\right)$, with the exception of dissolved nutrients, which are expressed as

227 milligrams of nitrogen per cubic meter $\left(\mathrm{mg} \mathrm{N} \mathrm{m}^{-3}\right)$. The equations of the model are based on

228 Kremer and Nixon (1978), a brief description of the different terms is given in Table 1 and a 
229 detailed description as well as the exact values of the parameters are given in Grant et al.

230 (1993, 2007a, 2008), Dowd (1997, 2005) and Filgueira and Grant (2009). The differential

231 equations are as follows:

232

$$
\frac{d P}{d t}=+P_{\text {growth }}-P_{\text {mortality }}-M_{\text {grazing }} \pm P_{\text {mixing }}
$$

$$
\frac{d N}{d t}=+N_{\text {river }}+M_{\text {excretion }}-P_{\text {uptake }} \pm N_{\text {mixing }}
$$

$$
\frac{d D}{d t}=+D_{\text {resuspension }}+M_{\text {feces }}+P_{\text {mortality }}-D_{\text {sinking }}-M_{\text {grazing }} \pm D_{\text {mixing }} \quad \text { Eq. } 3
$$

$$
\frac{d M}{d t}=+M_{\text {net growth }}+M_{\text {seeding }}-M_{\text {mortality }}-M_{\text {harvesting }}=0
$$

236 The mussel compartment biomass is assumed to be constant over time, so that the mussel biomass interacts with the ecosystem model as a forcing function rather than a response variable (Dowd, 2005). By manipulating forcing by mussel biomass, some of the more uncertain steps related to aquaculture activity are not required (for example, farming processes like harvesting and seeding, or bivalve size distribution). In addition, bivalve mortality rate is not explicit in the model. In essence, this assumption means that the growth of the bivalves and seeding activity is compensated by mortality rate and harvesting, providing the constant biomass.

245 The model was run between 15 June and 15 September for two years, 1998 and 1999. The

246 main differences between both years are related to suspended detritus content and wind 247 speed. Average organic detritus content of $857 \pm 250 \mathrm{mg} \mathrm{C} \mathrm{m}^{-3}$ and $565 \pm 193 \mathrm{mg} \mathrm{C} \mathrm{m}^{-3}$ was observed in 1998 and 1999, respectively. In addition, the percentage of days with wind speeds higher than $5 \mathrm{~m} \mathrm{~s}^{-1}$, the threshold for bottom resuspension (Filgueira and Grant, 2009;

250 Walker and Grant, 2009), was $8.89 \%$ and $2.22 \%$ in 1998 and 1999, respectively. Waite et al. 
251 (2005) and Filgueira and Grant (2009) provide further details of the model as well as the 252 boundary conditions.

254 Ground-truthing was carried out by comparing the modelled chlorophyll values in Element \# 255182 (See Figure 3 for location) with observations in both years, 1998 and 1999. The time 256 series were analyzed with major axis regression method (RMA) following Duarte et al. 257 (2003). The significance of the regression was tested using ANOVA and comparison of the 258 slope and intercept with 1 and 0, respectively, carried out following Zar (1984).

\section{Results}

\subsection{Ground-truthing}

263 The average measured water speed values and standard deviation were higher than the modelled values (Table 2), because current meter dataset contains extreme values, caused by strong local winds, which exert a bias in the time series comparison. A better indicator of central tendency for skewed distributions is the median, which minimizes the contribution of

267 extreme values and outliers. Median values of the model, $4.18 \mathrm{~cm} \mathrm{~s}^{-1}$, were in good agreement with the current meter values, $4.48 \mathrm{~cm} \mathrm{~s}^{-1}$, suggesting that the circulation model realistically reproduced the hydrodynamics.

271 The calculation of the first order upwind scheme error (Appendix B) in the chlorophyll

272 compartment resulted in an averaged value over the elements and time of $0.029 \%$ (maximum $2731.005 \%$ ) and $0.097 \%$ (maximum $1.738 \%$ ) respectively, which is an excellent indication that 274 cell size and daily averaging time step are small enough. In addition, the verification test 
275 described (Section 2.3) was performed in order to verify that Simile is correctly assimilating

276 the hydrodynamics from AquaDyn. Both models were set up with a constant tracer

277 concentration in the boundary of 2 units $\mathrm{m}^{-3}$ and an initial tracer concentration in the domain

278 of 1 unit $\mathrm{m}^{-3}$. The distribution of the tracer after 10 days (Figure 4) shows a similar pattern in

279 both AquaDyn and Simile. The largest discrepancies between both approaches are located in

280 the northeastern part of the bay. Two elements (See Figure 3 for location) were analyzed in

281 detail for a longer period of time, one located in the northeastern part of the bay (element

282 385) and another located in the southern section (element 182). Original AquaDyn time series

283 were transformed by applying a moving average regression in order to smooth high

284 frequency events with a period lower than one day (e.g. wind and tides), in order to provide

285 an average value for each day (Figure 5). This analysis highlights the better agreement in the

286 southern section, element 182. However, the discrepancies between AquaDyn and Simile in

287 the northern section, element 385, become smaller with time. Although the tracer is slightly

288 different in this element after 30 days, this convergence pattern and the similar spatial

289 distribution indicate that Simile is properly assimilating the AquaDyn output of the

290 hydrodynamics.

291

292 Ground-truthing of the coupled physical-biogeochemical model was carried out by

293 comparing modelled and observed values of chorophyll. The ANOVAs indicated that the

294 regressions $\left(1998:\right.$ Modelled $=1.13 \pm 0.14$ Observed $+11.95 \pm 17.14, \mathrm{r}^{2}=0.47, \mathrm{p}<0.05 ; 1999$ :

295 Modelled $=0.85 \pm 0.09$ Observed $\left.+36.34 \pm 25.78, \mathrm{r}^{2}=0.52, \mathrm{p}<0.05\right)$ are statistically significant.

296 Analysis of the slopes showed that in 1998 the model follows the same pattern as the

297 observations ( $\mathrm{p}=0.356)$. However, in 1999 the slope was less than $1(\mathrm{p}<0.05)$, indicating that 
298 the results of the model are offset from the observations. The intercepts are greater than 0

299 indicating that the model is slightly enriched in chlorophyll compared to the observed values.

300

301

\subsection{Model results}

302 The physical-biogeochemical model was run between 15 June and 15 September in two 303 scenarios for each year (1998 and 1999): without mussels and with a mussel standing stock of

$3041 \times 10^{6} \mathrm{~kg}$ wet weight, the minimum biomass in Tracadie Bay according to previous studies 305 (Dowd, 2003, 2005). Model outputs are shown as the percentage of chlorophyll depletion in 306 the mussel scenarios compared to the non-mussel scenario. The bay-averaged chlorophyll 307 depletion over the studied period ranged from $4.8 \%$ to $44.4 \%$ and $10.3 \%$ to $58.6 \%$ in 1998 308 and 1999, respectively (Figure 6). The maximum daily depletion observed in an element in 309 the bay was $61.0 \%$ and $80.3 \%$ for 1998 and 1999, respectively. The time-averaged 310 chlorophyll depletion for the whole bay was $26.6 \pm 8.1 \%$ and $30.0 \pm 8.8 \%$ for 1998 and 1999 , respectively. These differences are caused by the variation in boundary forcing conditions

312 between years. The time-averaged chlorophyll depletion (Figure 7) is related to the culture 313 area displaying decreases in depletion in the direction of nutrient sources, i.e. toward Winter

314 River and the inlet (Gulf Saint Lawrence), where culture density is negligible. In addition, the 315 effect of different boundary conditions between years can be observed, showing more intense and extended chlorophyll depletion in 1999 compared to 1998.

\section{Discussion}

320 The ability to couple physical and biogeochemical models is fundamental to simulating marine ecosystems. These coupling schemes can be classified as 'integration', 'online 
322 coupling' and 'offline coupling'. Integration refers to utilizing physical exchange in a

323 reduced spatial resolution, e.g. rates averaged across space for a box model. At the other end

324 of the linkage spectrum between physics and biogeochemistry, online coupling indicates that

325 both physical and biogeochemical models run simultaneously. In between are offline

326 coupling techniques, where the physics is run first and the biogeochemical model is run

327 subsequently using physical outputs at different time steps but the same spatial scale. Fully

328 spatial models constructed in VMEs require offline coupling given the limited connectivity

329 with physical simulation software. Our motivation in the present study is to provide insight

330 into the integration of physical and ecological data using a visual modelling environment

331 (VME), which, to our knowledge, is the first example in the literature in which a VME is

332 used to generate a fully spatial model.

334 There are other approaches in the literature (Table 3) that usually require expertise in

335 language programming and/or specific sophisticated software to create/modify modules, and

336 in some cases the structure of these modules is rigid and non-modifiable. The coupling

337 scheme described in this paper represents a novel approach to create fully-spatial models

338 using a Visual Modelling Environments (VME). VMEs such as Stella or Simile have

339 commonly been used in scientific literature given their smooth learning curve. VMEs are

340 based in objects that represent stocks, flows, variables and their interactions. The connections

341 of these objects symbolize ecological processes, and the fact that they can be visualized

342 facilitates access to non-programmers. These visual symbols make it easier to spread and

343 share models in the scientific community, a cornerstone for improving the conceptual design

344 of any model. 
346 The general scheme described in this paper constitutes a generic and flexible core for

347 coupling physical-biogeochemical models in coastal areas. The specifics of the ecosystem

348 model are initially developed in Simile and the submodels described in this paper allow the

349 coupling of hydrodynamics constructed in a different modelling environment, which can be

$3502 \mathrm{D}$ or 3D. In fact, the described scheme is quite flexible and can be used with only a few cells

351 to construct a box model. When the coupling scheme is applied to a new site, the

352 biogeochemical model can be re-used and the principal effort is focused on the hydrodynamic

353 model. Once the model is developed, the results can be exported to GIS for mapping,

354 increasing the connectivity of the model with other applications. Another advantage of the

355 coupling scheme developed in Simile is that the optimization tool PEST (Model-Independent

356 Parameter ESTimation, Watermark Numerical Computing) is integrated into Simile. PEST

357 can be used with two objectives in mind: (1) tune parameters in order to calibrate the model,

358 avoiding "eyeball" calibrations, or with the appropriate dataset estimates unknown or

359 uncertain parameters, and (2) optimize management strategies according to a variety of

360 criteria (e.g. Filgueira et al., 2010).

362 The coupling technique used in Simile follows an offline unidirectional scheme, that is, the

363 hydrodynamic model is run first and the results are delivered to the biogeochemical model

364 that is run subsequently, without providing feedback to the hydrodynamic model. This is not

365 a problem in this particular case given that the feedback of the biogeochemical model is not

366 relevant for the hydrodynamics of the bay. In fact, in shallow waters, tides, winds and

367 freshwater, runoff drives components of the circulation (Kjerfve and Magill, 1989). The

368 hydrodynamics are averaged following a first-order upwind scheme before being delivered to

369 the biogeochemical model. Since this averaging process dilutes the effect of high frequency 
events, the application of the model scheme is limited to the study of long-term processes.

371 These aspects of offline coupling must be taken into account when the general goals are set.

373 The described coupling scheme was applied to Tracadie Bay, a shallow bay with extensive 374 aquaculture activity. This application is presented as an example of the coupling scheme and 375 not as a research exercise itself. The bay is an excellent test bed because we have conducted a 376 variety of field and modellling studies there. Grant et al. (2008) employed a model of seston 377 depletion in Tracadie Bay in which AquaDyn results were coupled with a Matlab ecosystem model. Although specific to average seasonal nutrient, temperature, and boundary conditions, maps of seston depletion (Figure 4B in Grant et al., 2008) show near-identical patterns to 380 those depicted in Figure 7. In addition, the chlorophyll depletion values of $61.0 \%$ and $80.3 \%$ 381 for 1998 and 1999, respectively, are in good agreement with the values observed by Grant et al. (2007b, 2008) in the same bay during a short-term experiment. These authors predicted a $67 \%$ reduction in chlorophyll in the north-south transect of Tracadie bay, the main axis of the bay where mussel culture is located.

The approaches to shellfish aquaculture models can be divided into box models and fullyspatial physical-biogeochemical models (Grant and Filgueira, in press). Although it is possible to simplify hydrodynamics and include them in a box model, the spatial detail provided by a fully-spatial physical-biogeochemical model is desirable for two reasons. (1) high spatial resolution allows us to simulate the effects of farm location on the ecosystem and

391 the interaction between farms (e.g. Figure 7). Therefore, management policies related to 392 spatial arrangement of farms can be pursued as well as a prediction of bivalve growth rate as a function of culture biomass in each location. (2) The results can be mapped, an obvious 
394 advantage for representing trends and gradients in marine systems. Spatial resolution can also 395 affect the results of the model, especially when processes are dependent on concentration 396 (Fennel and Neumann, 2004).

398 In conclusion, we have focused on Simile, which incorporates a graphical user interface, is an 399 object-oriented software, and offers the capability of topology recognition using matrices, an 400 ideal modelling platform from which to pursue physical-biogeochemical simulation. The coupling scheme has satisfied tests of internal and external consistency and conservative behavior, and shown results compatible with previous field and modelling studies of the test location. The Simile coupling scheme has the following positive characteristics: (1) the

404 biogeochemical model can be modified by way of a user-friendly graphical interface; (2) 405 knowledge of programming language is minimized; (3) results can be exported to GIS, and 406 (4) an optimization tool (PEST) is integrated. Therefore, the proposed core developed in 407 Simile is a generic and flexible tool for modelling long-term processes in coastal waters, 408 which is able to assimilate a choice of hydrodynamic models, constituting a novel approach 409 for generating fully-spatial models using visual modelling environments.

\section{Acknowledgements}

413 This research was funded by a Strategic Project Grant and Discovery Grant from the Natural

414 Sciences and Engineering Research Council of Canada (NSERC) to JG. RF salary was

415 supported by an Angeles Alvariño (Xunta de Galicia) contract and a Xunta de Galicia

416 fellowship co-funded by the European Social Fund (Operative Program Galicia 2007-2013). 


\section{Appendix A. Software description}

418 Simile is a graphical system-dynamics modelling tool that incorporates object-oriented

419 concepts. The software is available from Simulistics Ltd. Visit http://www.simulistics.com or

420 email info@simulistics.com for details. Simile is available for Windows (95 onwards), Linux

421 (all) and MacOS (OSX 10.3 onwards). It takes between 20 and $50 \mathrm{MB}$ of disk space

422 depending on the platform. Simile has a proprietary license but its data formats are open.

423 Models can be freely distributed, and those built with Simile Enterprise can be run on a free

424 version of the software.

425

426 AquaDyn is a two dimensional free surface water hydrodynamic and dispersion software that

427 uses a finite element technique to solve the St-Venant equations. AquaDyn takes into account 428 bathymetry, bed friction, wind stress, turbulent dissipation and complex coastlines. The

429 software can be obtained from Hatch Ltd. Email or call Michel Carreau (mcarreau@hatch.ca; $430+1$ 514-864-5500 (ext. 6108)) for further details. The entire package once installed takes less

431 then 10 megabytes of space. Each model within AquaDyn is stored within one project file

432 which contains all inputs and outputs; the file size is typically smaller then 3 megabytes. The

433 software executable has been available since 1995 (the source code is not available for

434 distribution) and can be run on any Windows 32 bits operating system.

436 In addition to the validation performed by the developers, AquaDyn has been used and

437 validated in several studies carried out by our research group (Grant and Bacher, 2001; Grant 438 et al., 2005, 2008), various engineering consulting firms and schools (Belanger et al., 2000;

439 Ministère des resources naturelles - Québec, 2002). 


\section{Appendix B. Volumetric flow calculation (Matlab script available on request).}

442 Every node (shared vertex) within AquaDyn is represented with an $\mathrm{X}$ and Y Cartesian value

443 in the grid. For each node AquaDyn provides values for three quantities: water speed in x-

444 direction, water speed in y-direction and water depth at each time step. AquaDyn stores the

445 results in matrices that can be programmatically retrieved and manipulated. In an AquaDyn

446 model each element (grid cell) can be surrounded by a maximum of 3 elements and a

447 minimum of 1 element. Boundary elements always have less than 3 surrounding elements.

448 The exchange of water for a given element is defined in relation to each of the surrounding

449 elements in the mesh in terms of volumetric exchange. The volumetric flow through a link

450 from one element to another is calculated by multiplying the net velocity by the cross-

451 sectional area through the side:

452

453 Volumetric Flow $=$ (net velocity) $\mathrm{x}$ cross-sectional area

$454=$ (net velocity) $\mathrm{x}$ (average depth at the two nodes of the link) $\mathrm{x}$ (length of link)

455

456 The net velocity (nx.u+ny.v) is defined as the projection of the velocity vector $(u, v)$ at the 457 centre of each side (link) into the unit perpendicular vector of the link (nx, ny). The units of 458 the velocity vector $(\mathrm{u}, \mathrm{v})$, where $\mathrm{u}$ is the average velocity in the $\mathrm{x}$-direction at the two ends of 459 the link and $\mathrm{v}$ is similarly defined for the $\mathrm{y}$ direction, are adjusted to meters per day, which 460 are compatible with Simile time steps. The unit perpendicular vector (nx, ny) is defined to

461 point towards the centre of the element (Figure B.1a). Therefore a positive/negative net 462 velocity indicates that flow is into/out of the element. 
464 Taking into account the node coordinates, $(\mathrm{xA}, \mathrm{yA})$ and $(\mathrm{xB}, \mathrm{yB})$, the (nx, ny) vector is 465 calculated as follows (Figure B.1a):

466

467

$\mathrm{nx}=-(\mathrm{yA}-\mathrm{yB}) /\left[(\mathrm{xA}-\mathrm{xB})^{2}+(\mathrm{yA}-\mathrm{yB})^{2}\right]^{0.5}$

468

ny $=(x A-x B) /\left[(x A-x B)^{2}+(y A-y B)^{2}\right]^{0.5}$

469

or

470

$\mathrm{nx}=(\mathrm{yA}-\mathrm{yB}) /\left[(\mathrm{xA}-\mathrm{xB})^{2}+(\mathrm{yA}-\mathrm{yB})^{2}\right]^{0.5}$

471

ny $=-(x A-x B) /\left[\left((x A-x B)^{2}+(y A-y B)^{2}\right]^{0.5}\right.$

472

473 In order to compute which of the vectors is directed into the element, the (nx, ny) vector must

474 be compared with the direction of the vector ( $\mathrm{px}$, py), whose origin is the middle of the link

475 and terminus is the opposite node (Figure B.1b). If the quantity nx.px+ny.py is positive, (nx,

476

ny) and (px, py) follow the same direction into the element, and vice versa for negative

477 values.

478

479 AquaDyn provides a time series for water velocity and depth at each node, and the protocol

480 described above can be applied to each time step. However, in Simile the coupling is

481 simplified and the Matlab script delivers to AquaDyn the volumetric water exchange as a

482 daily average for each link following a first order upwind scheme. The error of this scheme is

483 kept to a minimum if the spatial and temporal variation of the concentration of a conservative

484 tracer remains small for each element and time step:

485

$$
\text { Error }_{\text {spatial }}(\%)=\left(\frac{\mid \Delta \text { Conc. } \mid}{\overline{\text { Conc. }}}\right)_{\text {spatial }}^{2} x 100
$$




$$
\text { Error }_{\text {time }}(\%)=\left(\frac{\mid \Delta \text { Conc. } \mid}{\overline{\text { Conc. }}}\right)_{\text {time }}^{2} x 100
$$

487 where $\mid \Delta C$ Conc. $\mid$ is the absolute difference in concentration between two connected elements at a given time (Eq. B.1), or between two time steps for the same cell (Eq. B.2). $\overline{\text { Conc. }}$ is the mean concentration of both values for each case. The calculation of this error is crucial in evaluating the general error of the coupling scheme.

492 The numerical procedure carried out to calculate the exchange and the averaging process can cause a residual water imbalance within the bay. Therefore, a minimization algorithm under

494 constraint (pinv function in Matlab) was applied to the averaged exchange in order to

495 minimize the water imbalance (to make the net flows zero) while keeping the correction

496 factors as small as possible (script available on request). After this process, two CSV files are 497 created, one with the averaged volume $\left(\mathrm{m}^{3}\right)$ of each element, the other with the averaged

498 volumetric exchange rates $\left(\mathrm{d}^{-1}\right)$, Exchange-Entry and Exchange-Exit, as well as the 499 identification numbers of Entry-Box and Exit-Box, i.e. which elements are linked. This CSV

500 file contains one row for each link, i.e between every adjacent element pair and therefore 501 defines the spatial connections between them in a way interpretable by Simile. 


\section{Appendix C. Simile structure to read spatial information (Files available on request).}

504 The use of 'Condition' requires variables to identify multiple instances saved in arrays inside

505 Simile or in external CSV files. These index variables, Entry-Box and Exit-Box, are used to

506 identify associations between elements in the grid and the calculated water volumetric

507 exchange rates, Exchange-Entry and Exchange-Exit, to incorporate the hydrodynamics.

508

509 The following example, considering the dynamics of total suspended particulate matter

510 (TPM, turbidity) in a bay (Figure C.1) provides a template that can be used as a core to

511 develop any application of the coupling scheme in Simile. The 'number of instances' (an

512 innate property of all submodels in Simile) of the Bay submodel was modified to create $n$

513 copies that represent the $n$ elements of the spatial grid. Two submodels were created to

514 manage the Inflow and Outflow of TPM and another one, Connections, that allows loading of

515 external data from CSV files by using 'Fixed Parameter' variables. The Connections

516 submodel has a 'number of instances' equal to the number of connections between elements,

517 i.e. the number of rows of the external CSV file. Inflow and Outflow submodels were related

518 with 'Exclusive Role' to the Connections submodel and 'Normal Role' to the Bay submodel.

519 The Inflow and Outflow submodels establish if there is a connection between any two

520 elements by means of the 'Condition' functions (Cond1 and Cond2 in Figure C.1). For

521 example, the Inflow submodel checks if the Box_Number variable from the Bay submodel

522 matches the Entry-Box variable value (which depends on the rows of the external CSV file).

523 If there is a match, the corresponding Exit-Box (the same row as the Entry-Box value) is

524 matched with the appropriate Box_Number in the Bay submodel. Given these prescribed

525 connections, the flow exchange is taken from the same row of the CSV file as the data input

526 (Exchange-Entry and Exchange-Exit). Once these exchanges are established, the physical- 
527 material coupling is completed. Therefore if an element exports TPM, the appropriate mass

528 flux of TPM (concentration * exchange) will be removed from the TPM compartment and the 529 same amount of TPM will be added to the element that receives the TPM. All the rows of the

530 CSV file, exchange between elements, are processed by Simile at the same time, therefore the 531 hydrodynamic of the whole bay is coupled simultaneously, preserving continuity in the 532 system.

533

534 Although hydrodynamics are coupled with the biogeochemical model as described above, a 535 fully-spatial model requires that individual variables also be initialized in space, e.g. the 536 initial concentration of TPM in each element. Figure C. 2 shows the same model with the 537 addition of two new submodels to introduce the initial TPM value in each element. This is 538 accomplished using an external CSV file which contains two columns, the element index 539 variable and the initial TPM value in that element (Box and Initial TPM Value, respectively).

540 The submodel called Initial TPM reads these variables from an external CSV file using

541 'Fixed Parameter' variables. The submodel called Initial Condition checks if the

542 Box_Number variable from the Bay submodel matches the Box variable value from the Initial

$543 T P M$ submodel (which depends on the rows of the external CSV file). If there is a match the

544 Initial TPM Value will be introduced into the Bay submodel as the initial value of TPM for 545 the Box_Number element. The same procedure can be applied to other variables, such as the 546 presence/absence of aquaculture, providing a very fine spatial resolution of the initial 547 conditions. 


\section{References}

549 Allen, J.I., Aiken, J., Anderson, T.R., Buitenhuis, E., Cornell, S., Geider, R.J., Haines, K., 550 Hirata, T., Holt, J., Le Quere, C., Hardman-Mountford, N., Ross, O.N., Sinha, B., While, J., 551 2010. Marine ecosystem models for earth system applications: The MarQUEST experience. 552 J. Marine. Syst. 81, 19-33.

554 Bacher, C., Duarte, P., Ferreira, J.G., Héral, M., Raillard, O., 1998. Assessment and 555 comparison of the Marennes-Oléron Bay (France) and Carlingford Lough (Ireland) Carrying 556 Capacity with ecosystem models. Aquat. Ecol. 31, 379-394.

558 Bacher, C., Grant, J., Hawkins, A., Fang, J., Zhu, P., Duarte, P., 2003. Modelling the effect of 559 food depletion on scallop growth in Sungo Bay (China). Aquat. Living. Resour. 16, 10-24.

561 Baretta, J.W., Ebenhoh, H., Ruardij, P., 1995. The European-regional-seas-ecosystem-model, 562 a complex marine ecosystem model. Neth. J. Sea. Res. 33, 233-246.

564 Behm, P., Boumans, R.M.J., Short, F.T., 2004. Spatial modeling of eelgrass distribution in

565 Great Bay, New Hampshire, in: Constanza, R., Voinov, A. (Eds.), Landscape simulation 566 modelling. A spatially explicit, dynamic approach. Springer-Verlag, New York, pp. 173-196.

568 Belanger, M., Carreau, M., Vincent, A. 2000. A test field calibration to validate shallow569 water codes: the case of the Ste- Marguerite River with AquaDyn. Centre de Recherche en 570 Calcul Applique (CERCA) Technical Report TR-2006-01, University of Montreal. 
572 Chapelle, A., Lazure, P., Menesguen, A., 1994. Modeling eutrophication events in a coastal 573 ecosystem - sensitivity analysis. Estuarine Coast. Shelf Sci. 39, 529-548.

574

575 Chapelle, A., Menesguen, A., Deslous-Paoli, J.M., Souchu, P., Mazouni, N., Vaquer, A., 576 Millet, B., 2000. Modelling nitrogen, primary production and oxygen in a Mediterranean 577 lagoon. Impact of oysters farming and inputs from the watershed. Ecol. Model. 127, 161-181.

578

579 Cloern, J.E., 1982. Does the benthos control phytoplankton bio- mass in southern San 580 Francisco Bay? Mar. Ecol. Prog. Ser. 9, 191-202.

581

582 Cranford, P.J., Strain, P.M., Dowd, M., Hargrave, B.T., Grant, J., Archambault, M.C., 2007.

583 Influence of mussel aquaculture on nitrogen dynamics in a nutrient enriched coastal

584 embayment. Mar. Ecol. Prog. Ser. 347, 61-78.

585

586 Dowd, M., 1997. On predicting the growth of cultured bivalves. Ecol. Model. 104, 113-131.

587

588 Dowd, M., 2003. Seston dynamics in a tidal inlet with shellfish aquaculture: a model study

589 using tracer equations. Estuarine Coast. Shelf Sci. 57, 523-537.

590

591 Dowd, M., 2005. A bio-physical coastal ecosystem model for assessing environmental effects 592 of marine bivalve aquaculture. Ecol. Model. 183, 323-346.

593 
594 Duarte, P., Meneses, R., Hawkins, A.J.S., Zhu, M., Fang, J., Grant, J., 2003. Mathematical 595 modelling to assess the carrying capacity for multi-species culture within coastal waters. 596 Ecol. Model. 168, 109-143.

597

598 Elshorbagy, A., Teegavarapu, R.S.V., Ormsbee, L., 2006. Assessment of pathogen pollution 599 in watersheds using object-oriented modeling and probabilistic analysis. J. Hydroinform. 8, $600 \quad 51-63$.

601

602 Fennel, W., Neumann, T., 2004. Introduction to the modelling of marine ecosystems.

603 Elsevier Oceanography Series, 72. Elsevier, Amsterdam.

604

605 Fennel, K., Wilkin, J., Levin, J., Moisan, J., O’Reilly, J., Haidvogel, D., 2006. Nitrogen

606 cycling in the Middle Atlantic Bight: Results from a three-dimensional model and

607 implications for the North Atlantic nitrogen budget. Glob. Biogeochem. Cycles 20, GB3007, 608 doi:10.1029/2005GB002456.

609

610 Ferreira, J., Duarte, P., Ball, B., 1998. Trophic capacity of Carlingford Lough for aquaculture 611 - analysis by ecological modelling. Aquat. Ecol. 31, 361-379.

612

613 Ferreira, J.G., Hawkins, A.J.S., Monteiro, P., Moore, H., Service, M., Pascoe, P.L., Ramos,

614 L., Sequeira, A., 2008. Integrated assessment of ecosystem-scale carrying capacity in shelfish 615 growing areas. Aquaculture 275, 138-151.

616 
617 Filgueira, R., Grant, J., 2009. A box model for ecosystem-level management of mussel

618 culture carrying capacity in a coastal bay. Ecosystems 12, 1222-1233.

619

620 Filgueira, R., Grant, J., Strand, Ø., Asplin, L., Aure, J., 2010. A simulation model of carrying 621 capacity for mussel culture in a Norwegian fjord: role of forced upwelling. Aquaculture 308, 622 20-27.

623

624 Grant, J., Bacher, C., Cranford, P.J., Guyondet, T., Carreau, M., 2008. A spatially explicit 625 ecosystem model of seston depletion in dense mussel culture. J. Mar. Syst. 73, 1555-168. 626

627 Grant, J., Bugden, G., Horne, E., Archambault, M.-C., Carreau, M., 2007b. Remote sensing 628 of particle depletion by coastal suspension-feeders. Can. J. Fish. Aquat. Sci. 64, 387-390.

629

630 Grant, J., Cranford, P., Hargrave, B., Carreau, M., Schofield, B., Armsworthy, S., Buerdett631 Coutts, V., Ibarra, D., 2005. A model of aquaculture biodeposition for multiple estuaries and 632 field validation at blue mussel (Mytilus edulis) culture sites in eastern Canada. Can. J. Fish. 633 Aquat. Sci. 62, 1271-1285.

634

635 Grant, J., Curran, K.J., Guyondet, T.L., Tita, G., Bacher, C., Koutitonsky, V., Dowd, M., 636 2007a. A box model of carrying capacity for suspended mussel aquaculture in Lagune de la 637 Grande-Entrée, iles-de-la-Madeleine, Québec. Ecol. Model. 200, 193-206. 
639 Grant, J., Dowd, M., Thompson, K., Emerson, C., Hatcher, A., 1993. Perspectives on field 640 studies and related biological models of bivalve growth, in: Dame, R. (Ed.), Bivalve filter

641 feeders and marine ecosystem processes. Springer, New York, pp. 371-420.

642

643 Grant, J., Filgueira, R., (in press). The application of dynamic modelling to prediction of

644 production carrying capacity in shellfish farming, in: Shumway, S (Ed.), Shellfish

645 aquaculture and the environment. John Wiley \& Sons, New York.

646

647 Héral, M., 1993. Why carrying capacity models are useful tools for management of bivalve 648 molluscs culture, in: Dame, R. (Ed.), Bivalve filter-feeders in estuarine and coastal 649 ecosystems. NATO ASI Series, pp. 455-477.

650

651 Kjerfve, B., Magill, K.E., 1989. Geographic and hydrodynamic characteristics of shallow 652 coastal lagoons. Mar. Geol. 88, 187-199.

653

654 Kremer, J., Nixon, S.W., 1978. A Coastal Marine Ecosystem: Simulation and Analysis.

655 Springer-Verlag, New York.

656

657 Maxwell, T., Constanza, R., 1994. Spatial ecosystem modelling in a distributed 658 computational environment, in: van den Bergh, J., van der Straaten, J. (Eds.), Towards 659 Sustainable Development: Concepts, Methods, and Policy. Island Press, Washington DC. 660

661 Maxwell, T., Constanza, R., 1995. Distributed modular spatial ecosystem modelling. 662 International Journal of Computer Simulation 5, 247-262. 
664 Maxwell, T., Constanza, R., 1997a. An open geographic modelling environment. Simulation 665 Journal 68, 175-185.

666

667 Maxwell, T., Constanza, R., 1997b. A language for modular spatio-temporal simulation.

668 Ecol. Model. 103, 105-113.

669

670 Ministère des resources naturelles - Québec, 2002. Régularisation des crues du bassin versant 671 du lac Kénogami. Saguenay-Lac-Saint-Jean 621 1-01-005

672

673 Muetzelfeldt, R., Massheder, J., 2003. The Simile visual modelling environment. Eur. J.

674 Agron. 18, 345-358.

675

676 North, E.W., King, D.M., Xu, J., Hood, R.R., Newell, R.I.E., Paynter, K., Kellogg, M.L.,

677 Liddel, M.K., Boesch, D.F., 2010. Linking optimization and ecological models in a decision 678 support tool for oyster restoration and management. Ecol. Appl. 20, 851-866.

679

680 Pastres, R., Solidoro, C., Cossarini, G., Canu, D.M., Dejak, C., 2001. Managing the rearing of 681 Tapes philippinarum in the lagoon of Venice: a decision support system. Ecol. Model. 138, $682 \quad 231-245$.

683

684 Pereira, A., Duarte, P., 2005. EcoDynamo: Ecological Dynamics Model Application. DITTY 685 Report. Available at http://www.dittyproject.org/Reports.asp 
687 Pereira, A., Duarte, P., Norro, A., 2006. Different modelling tools of aquatic ecosystems: A 688 proposal for a unified approach. Ecol. Inform. 1, 407-421.

689

690 Raillard, O., Ménesguen, A., 1994. An ecosystem model for the estimating the carrying 691 capacity of a macrotidal shellfish system. Mar. Ecol. Prog. Ser. 115, 117-130.

692

693 Randhir, T.O., Tsvetkova, O., 2011. Spatiotemporal dynamics of landscape pattern and 694 hydrologic process in watershed systems. J. Hydrol. 404, 1-12.

695

696 Sarmiento, J.L., Slater, R.D., Fashman, M.J.R., Ducklow, H.W., Toggweiler, J.R., Evans, 697 G.T., 1993. A seasonal 3-dimensional ecosystem model of nitrogen cycling in the North698 Atlantic euphotic zone. Global Biochem. Cy. 7, 417-450.

699

700 Shchepetkin, A.F., McWilliams, J.C., 2005. The Regional Ocean Modelling SystemL A split701 explicit, free-surface, topography following coordinates ocean model. Ocean Model. 9, 347702404.

703

704 Silvert, W., 1993. Object-oriented ecosystem modeling. Ecol. Model. 68, 91-118.

705

706 Spillman, C.M., Hamilton, D.P., Hipsey, M.R., Imberger, J., 2008. A spatially resolved 707 model of seasonal variations in phytoplankton and clam (Tapes philippinarum) biomass in 708 Barbamarco Lagoon, Italy. Estuarine Coast. Shelf Sci. 79, 187-203. 
710 Umgiesser, G., Canu, D.M., Solidoro, C., Ambrose, R., 2003. A finite element ecological 711 model: a first application to the Venice Lagoon. Environ. Modell. Softw. 18, 131-145.

712

713 Waite, L., Grant, J., Davidson, J., 2005. Bay-scale spatial growth variation of mussels Mytilus

714 edulis in suspended culture, Prince Edward Island, Canada. Mar. Ecol. Prog. Ser. 297, 157-

715167.

716

717 Walker, T.R., Grant, J., 2009. Quatifying erosion rates and stability of bottom sediments at 718 mussel aquaculture sites in Prince Edward Island. J. Marine. Syst. 75, 46-55.

719

720 Zar, J.H., 1984. Biostatistical Analysis. New Jersey: Prentice-Hall.

721 


\section{Figure Legends}

723 Figure 1. Triangular unstructured finite grid example. A. Structure and nomenclature of the components of the grip. B. Additional points calculated to plot Simile results in GIS software.

725

726 Figure 2. Coupling scheme developed for Tracadie Bay: triangular finite grid created in

727 AquaDyn, example of water exchange file delivered by Matlab and description of the

728 structure developed in Simile, which combines the biogeochemical model and the submodel

729 that reads the spatial topology and executes the hydrodynamics.

730

731 Figure 3. Study area. A. Tracadie Bay (Prince Edward Island, Canada). B. Triangular 732 unstructured grid of Tracadie Bay created in AquaDyn. The circle represents Node \# 236, 733 where the current-meter was deployed, and the two coloured elements are Element \# 182 734 (South) and \# 385 (North), where the conservative tracer verifications were performed. 735

736 Figure 4. Conservative tracer concentration $\left(\right.$ units $\mathrm{m}^{-3}$ ) in Tracadie Bay after 10 days in 737 AquaDyn and Simile.

738

739 Figure 5. Time series of conservative tracer concentration (units $\mathrm{m}^{-3}$ ) in Element \# 182 and \# 740385 in AquaDyn and Simile.

741

742 Figure 6. Bay averaged time series of chlorophyll depletion (\%) in both 1998 and 1999.

743 Continuous line represents the average value and dotted lines the standard deviation.

745 Figure 7. Time averaged percentage of chlorophyll depletion (\%) in both 1998 and 1999. 
747 Figure B.1. Structure of the element defined by the nodes A (xA,yA), B (xB,yB) and C

$748(\mathrm{xC}, \mathrm{yC})$ and vectors used to calculate the flow through the link A-B. A. Perpendicular vector

749 (nx, ny) to the link A-B. B. Vector (px,py) which origin in the middle of the link A-B, D

750 (xD,yD), and directed to the opposite node of $\mathrm{A}-\mathrm{B}, \mathrm{C}(\mathrm{xC}, \mathrm{yC})$.

751

752 Figure C.1. Simile model of a bay in which only the TPM is considered. Inflow, Outflow and 753 Connections submodels provide the information to couple AquaDyn to Simile. The submodel 754 called Submodel - Legend describes the different symbols used in the model according to the 755 nomenclature used in Simile (Muetzelfeldt and Massheder 2003).

756

757 Figure C.2. Simile model with a submodel to establish initial values at the beginning of the 758 simulation. 

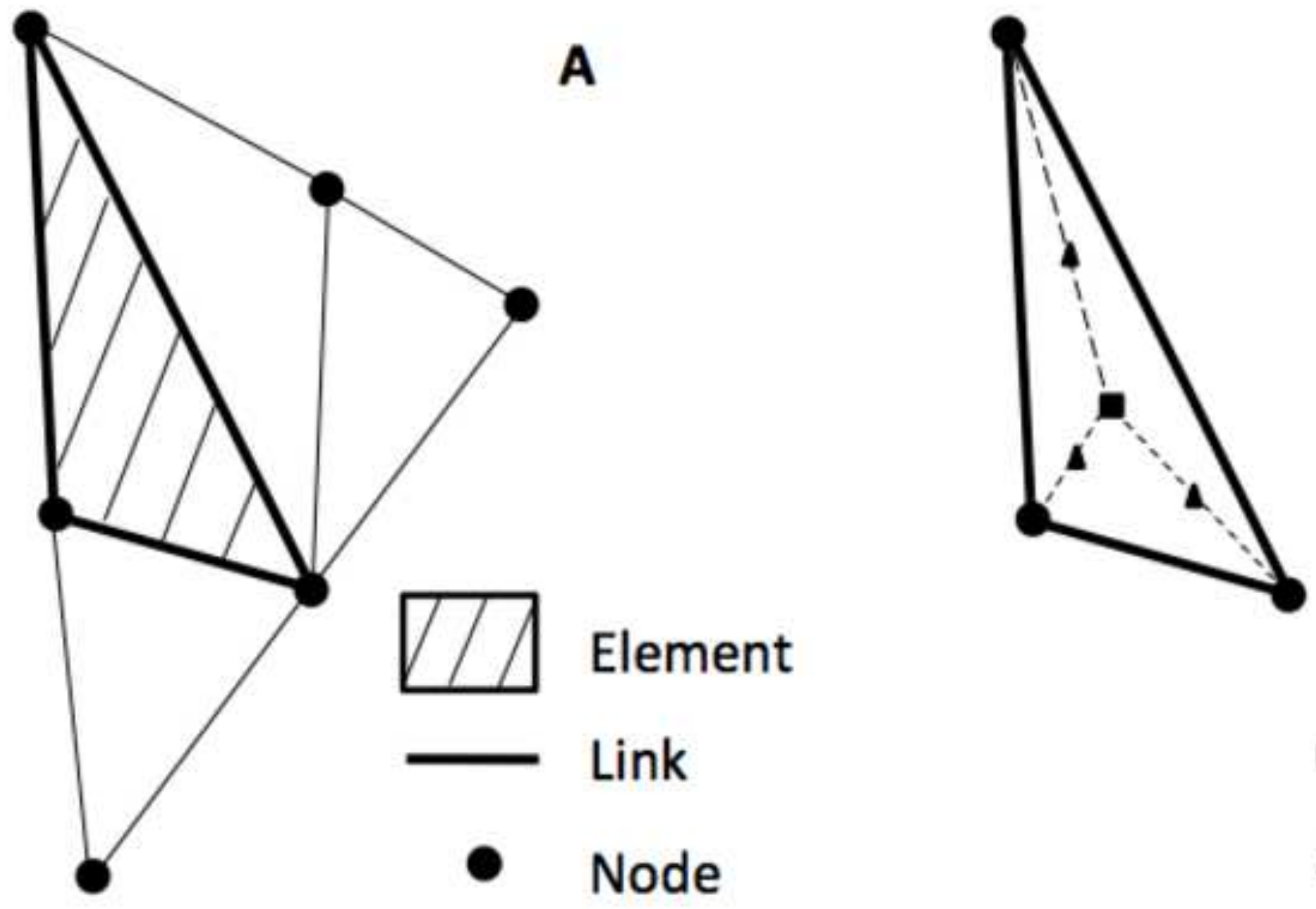

B

- Centroid

- Midpoint 

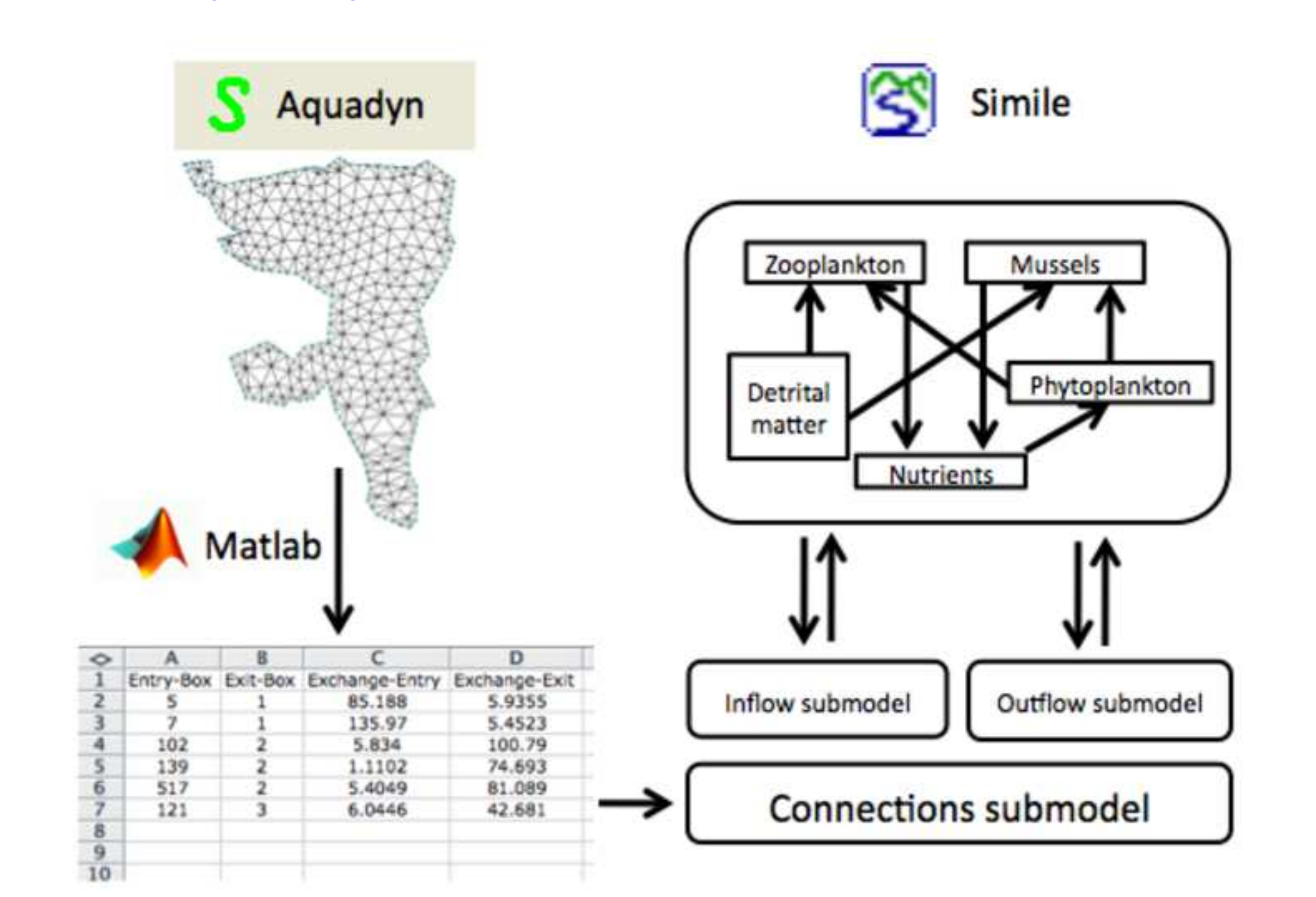

.


Click here to download high resolution image
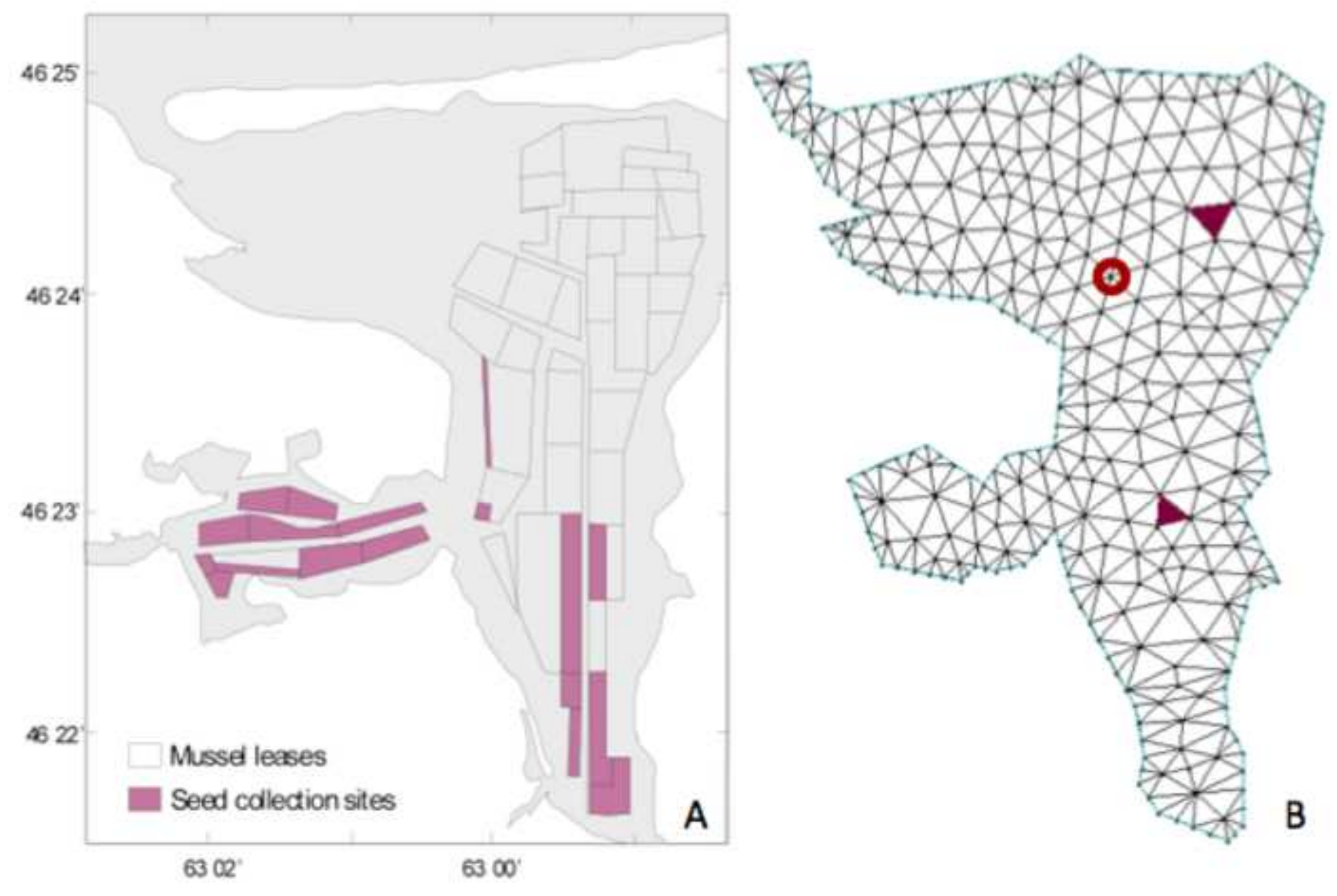

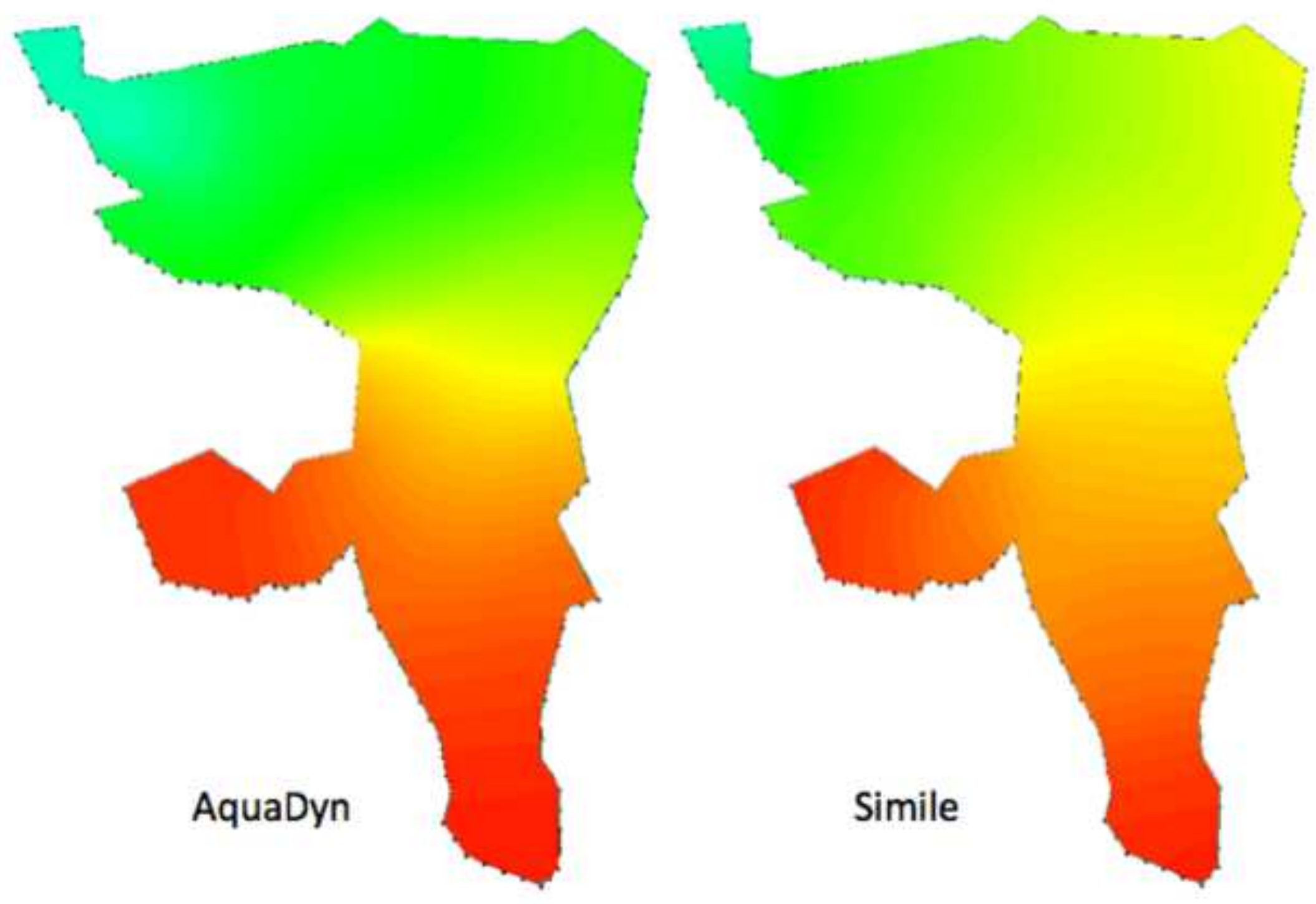


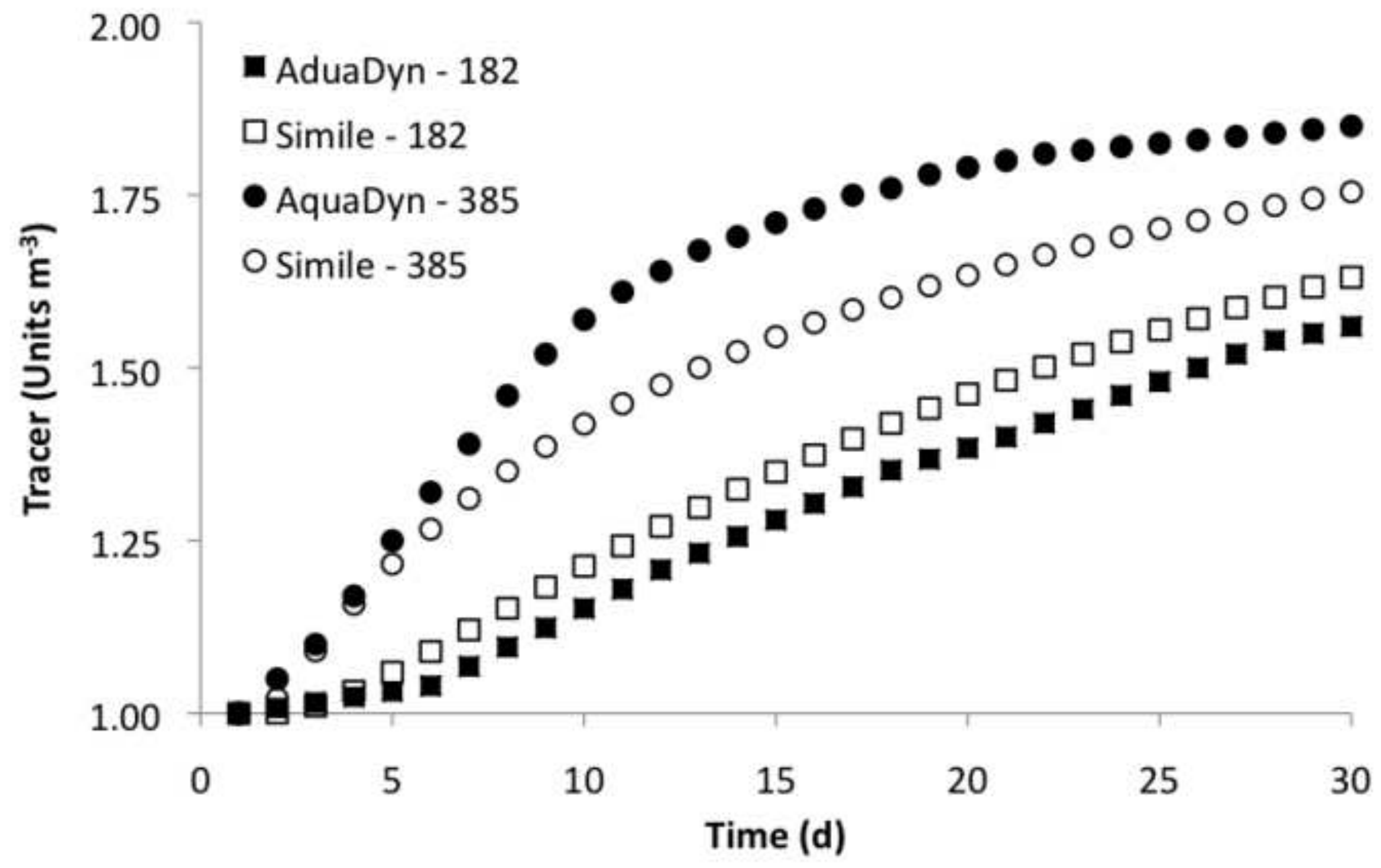


Click here to download high resolution image

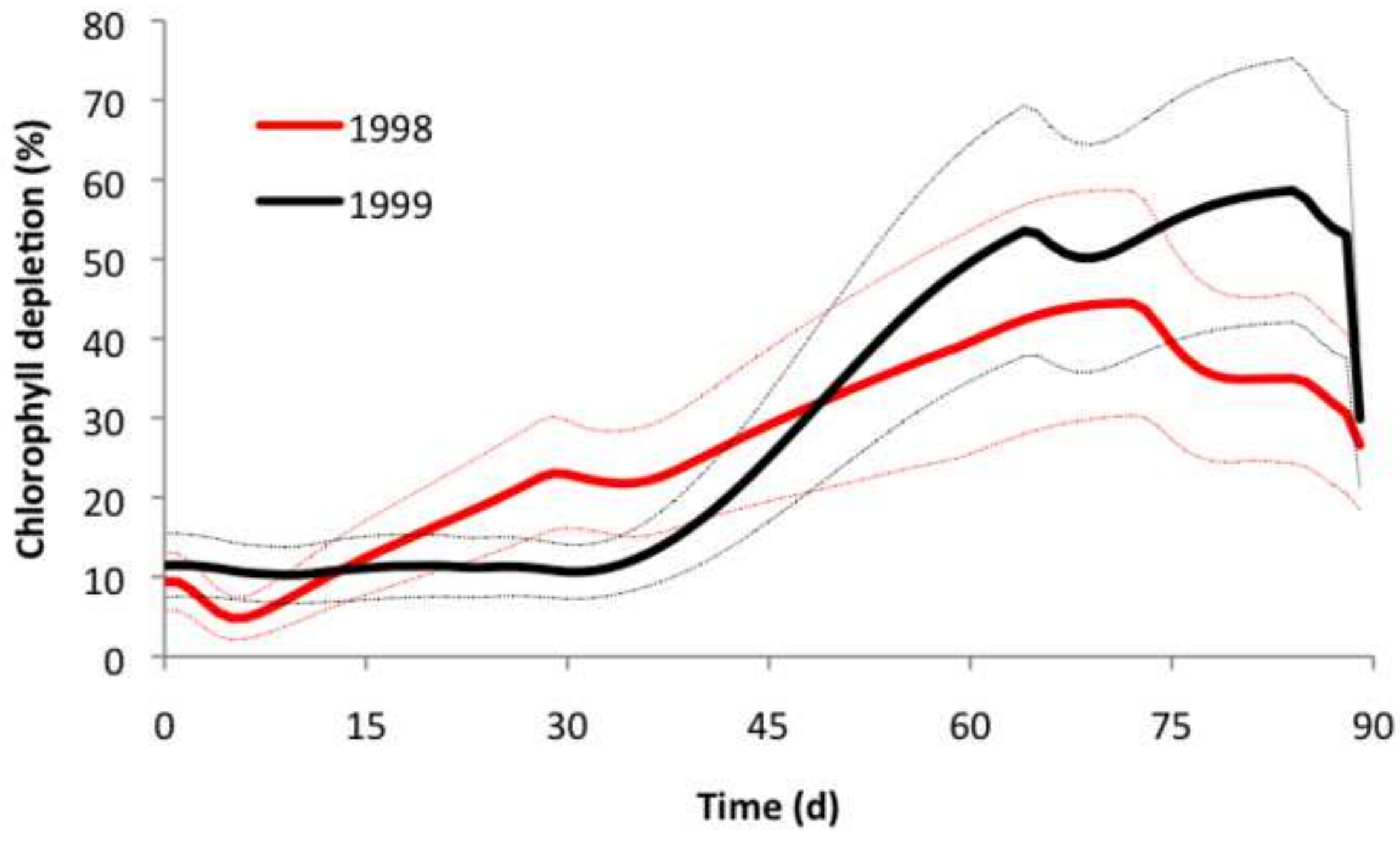



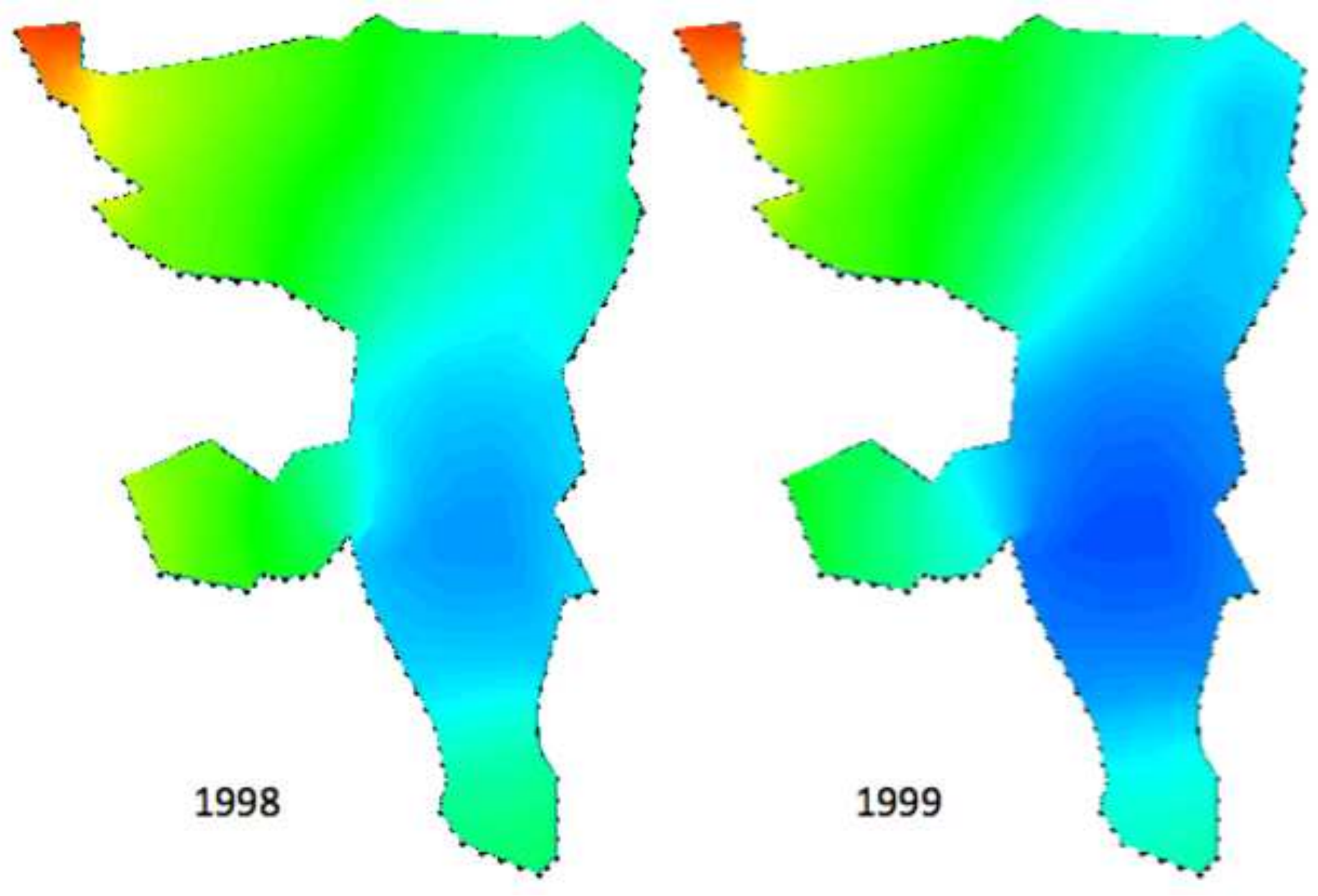

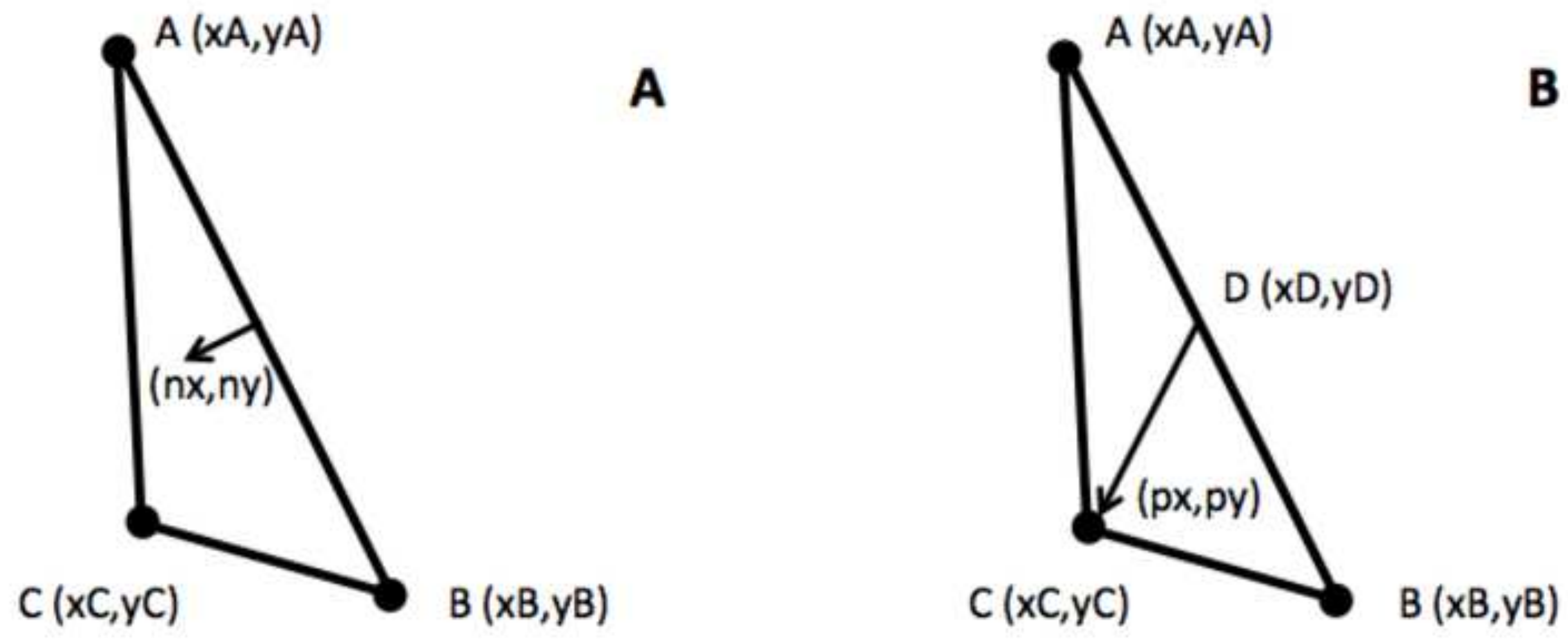


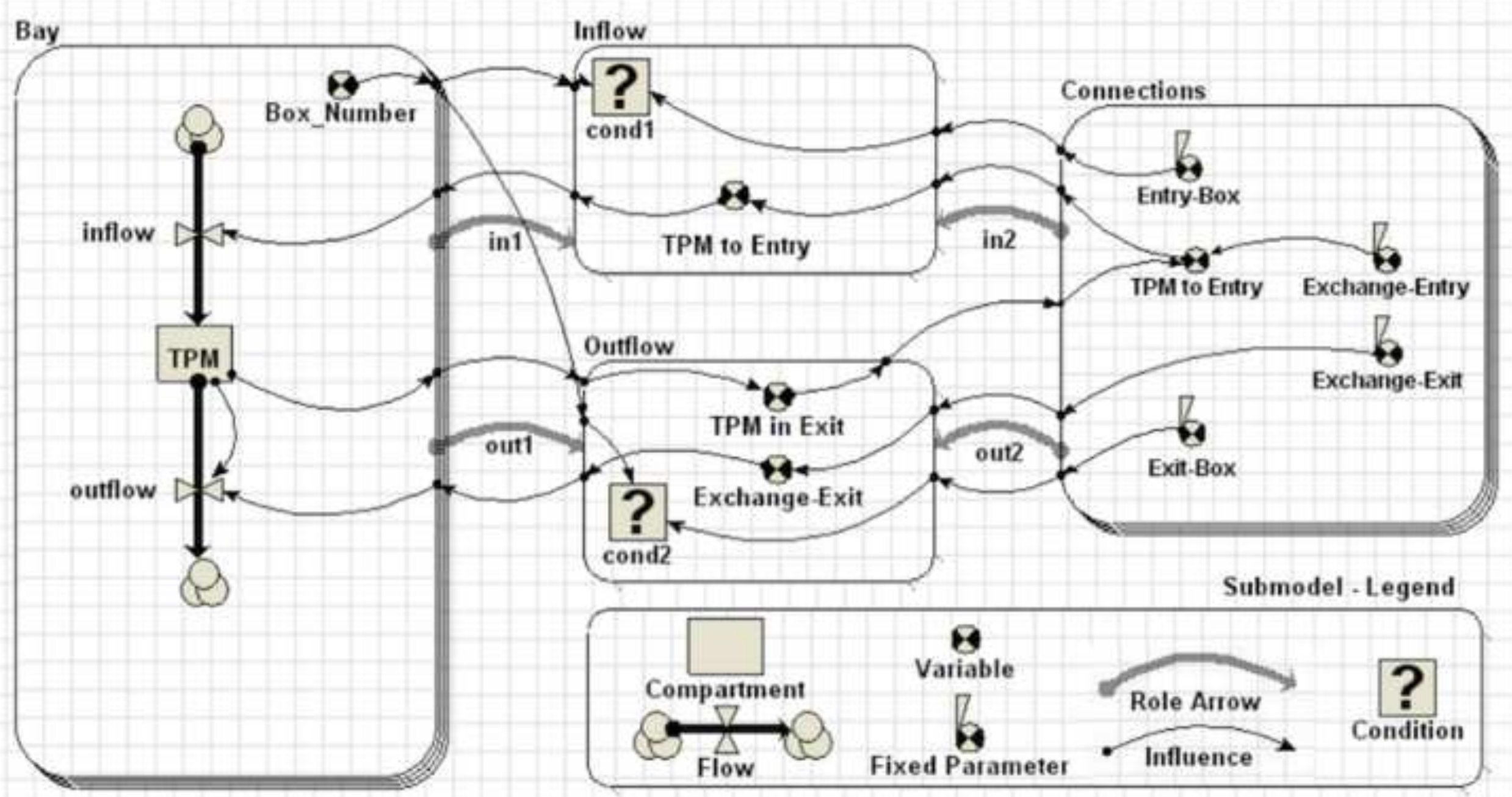




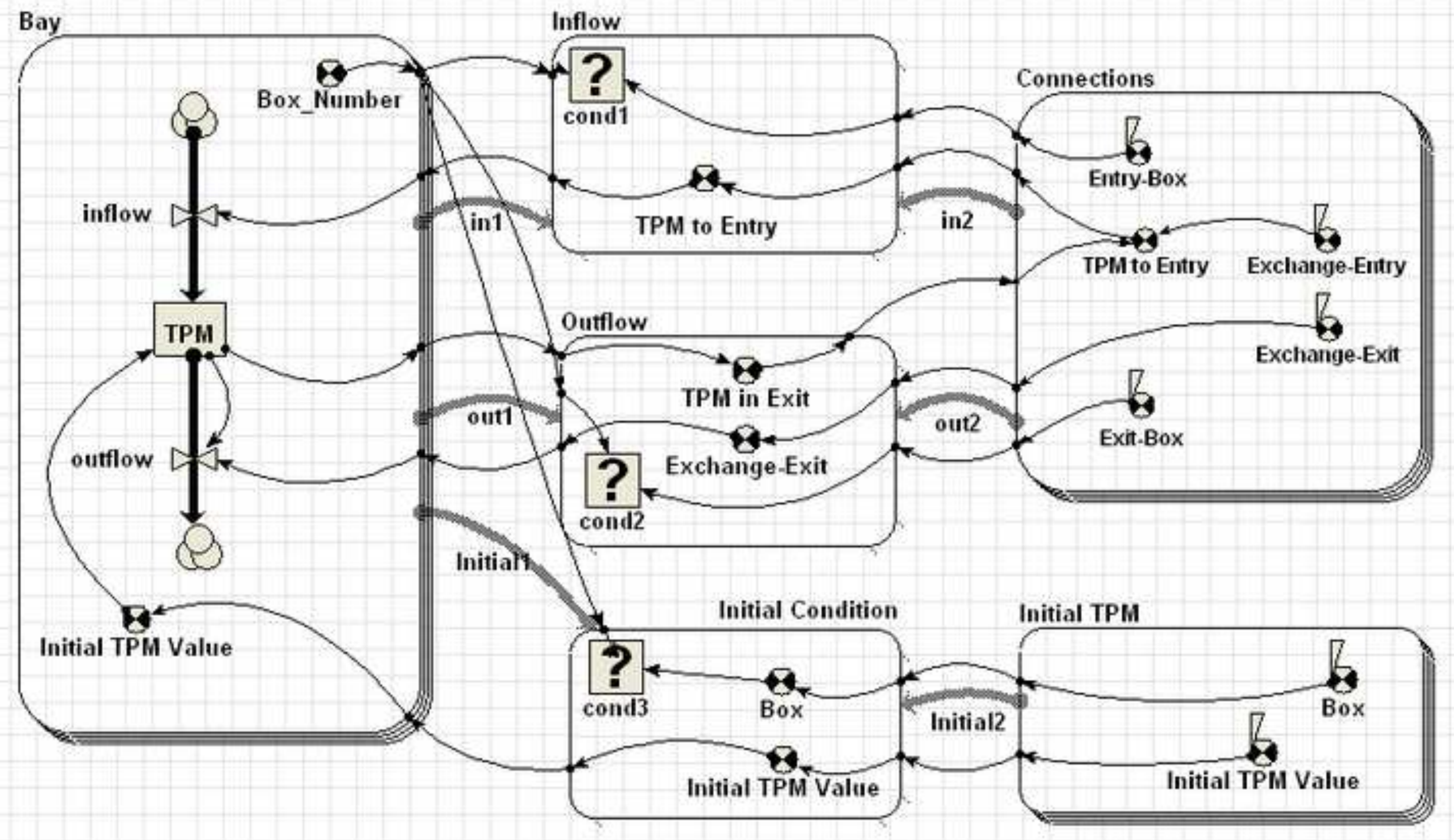


Table 1. General model equations and description.

\begin{tabular}{|c|c|c|}
\hline Term & Definition & Reference \\
\hline$d P / d t$ & $\begin{array}{l}\text { Phytoplantkton change rate }\left(\mathrm{mgC} \mathrm{m}^{-3}\right. \\
\left.\mathrm{d}^{-1}\right)\end{array}$ & \multirow{5}{*}{ Eq. 7 in Grant et al. (2007) } \\
\hline$P_{\text {growth }}$ & Phytoplankton growth & \\
\hline$P_{\text {mortality }}$ & Phytoplankton mortality & \\
\hline$M_{\text {grazing }}$ & Mussel grazing on phytoplankton & \\
\hline$P_{\text {mixing }}$ & $\begin{array}{l}\text { Exchange of phytoplankton with } \\
\text { adjacent elements and far field }\end{array}$ & \\
\hline$d N / d t$ & Nitrogen change rate $\left(\mathrm{mgN} \mathrm{m}^{-3} \mathrm{~d}^{-1}\right)$ & \\
\hline$N_{\text {river }}$ & Nitrogen river discharge & $\begin{array}{l}\text { River discharge } \mathrm{x} \text { River Nitrogen } \\
\text { concentration }\end{array}$ \\
\hline$M_{\text {excretion }}$ & Mussel nitrogen excretion & Eq. 17 in Grant et al. (2007) \\
\hline$P_{\text {uptake }}$ & Phytoplankton nitrogen uptake & \multirow[b]{2}{*}{ Eq. 15 in Grant et al. (2007) } \\
\hline$N_{\text {mixing }}$ & $\begin{array}{l}\text { Exchange of nitrogen with adjacent } \\
\text { elements and far field }\end{array}$ & \\
\hline$d D / d t$ & Detritus change rate $\left(\mathrm{mgC} \mathrm{m}^{-3} \mathrm{~d}^{-1}\right)$ & \\
\hline$D_{\text {resuspension }}$ & Detritus resuspension forced by wind & See Filgueira and Grant (2009) \\
\hline$M_{\text {feces }}$ & Mussel feces production & Eq. 5 in Grant et al. (2007) \\
\hline$P_{\text {mortality }}$ & Phytoplankton mortality & See above \\
\hline$D_{\text {sinking }}$ & Detritus removal by sinking & \multirow{3}{*}{ Eq. 5 in Grant et al. (2007) } \\
\hline$M_{\text {grazing }}$ & Mussel grazing on detrital matter & \\
\hline$D_{\text {mixing }}$ & $\begin{array}{l}\text { Exchange of detritus with adjacent } \\
\text { elements and far field }\end{array}$ & \\
\hline$d M / d t$ & Mussel change rate $\left(\mathrm{mgC} \mathrm{m}^{-3} \mathrm{~d}^{-1}\right)$ & \multirow{5}{*}{$\begin{array}{l}\text { Eq. } 1 \text { in Grant et al. (2007) } \\
\text { These rates are not calculated, } \\
\text { their sum is assumed to } \\
\text { compensate } M_{\text {net growth }}\end{array}$} \\
\hline$M_{\text {net growth }}$ & Mussel net growth & \\
\hline$M_{\text {seeding }}$ & Income of mussel biomass by seeding & \\
\hline$M_{\text {mortality }}$ & Mussel natural mortality & \\
\hline$M_{\text {harvesting }}$ & Mussel mortality by harvesting & \\
\hline
\end{tabular}


Table 2. Analysis of velocity modulus measured with the current meter $\left(46^{\circ} 23^{\prime} 56^{\prime}\right.$ ' $\mathrm{N}$, $62^{\circ} 59^{\prime} 56^{\prime}$ 'W) and the closest node in AquaDyn model, Node \# 236. Values are in $\mathrm{cm} \mathrm{s}^{-1}$.

\begin{tabular}{lcc}
\hline & Current Meter & AquaDyn \\
\hline Maximum & 21.57 & 7.66 \\
Minimum & 0.18 & 0.09 \\
Mean & 5.09 & 3.67 \\
Standard Dev. & 2.93 & 1.35 \\
Median & 4.48 & 4.18 \\
\hline
\end{tabular}


Table 3. Summary of different modelling environments, most relevant characteristics, classification of coupling and references.

\begin{tabular}{|c|c|c|c|}
\hline Modelling environment & Characteristics & Coupling & References / Examples \\
\hline \multicolumn{4}{|l|}{ General modelling environments } \\
\hline Spatial Modelling Environment & $\begin{array}{l}\text { Object oriented simulation environment } \\
\text { Specific programming language } \\
\text { Possibility to be coupled to other software }\end{array}$ & $\begin{array}{l}\text { Integration / } \\
\text { Offline }\end{array}$ & $\begin{array}{l}\text { Maxwell and Constanza, } \\
\text { 1994, 1995, 1997a, 1997b }\end{array}$ \\
\hline Matlab / Fortran & $\begin{array}{l}\text { Programming language } \\
\text { High flexibility and mathematical power } \\
\text { Possibility to be coupled to other software }\end{array}$ & $\begin{array}{l}\text { Integration / } \\
\text { Offline / } \\
\text { Online }\end{array}$ & $\begin{array}{c}\text { Fennel and Neumann, } 2004 \\
\text { Umgiesser et al., } 2003\end{array}$ \\
\hline GEMSS / ROMS & $\begin{array}{l}\text { Physical modelling environment } \\
\text { Possibility to use pre-generated, but usually non- } \\
\text { modifiable biological models }\end{array}$ & Online & Fennel et al., 2006 \\
\hline \multicolumn{4}{|l|}{ Aquaculture examples } \\
\hline Not specified & $\begin{array}{l}\text { Improve economic yield of Tapes phillipinarum } \\
\text { culture (Venice Lagoon) }\end{array}$ & Not specified & Pastres et al., 2001 \\
\hline EcoDynamo & $\begin{array}{l}\text { Simulate physical, biogeochemical and } \\
\text { anthropogenic processes in aquatic ecosystems } \\
\text { Possibility to be coupled to other software }\end{array}$ & Offline & Pereira et al. 2006 \\
\hline $\begin{array}{l}\text { EcoWin2000 /Delft3D-Flow / } \\
\text { ShellSIM }\end{array}$ & $\begin{array}{l}\text { EcoWin2000 is a platform for integration of } \\
\text { different submodels or software } \\
\text { Evaluate carrying capacity for aquaculture } \\
\quad \text { (Northern Irleand) }\end{array}$ & Offline & Ferreira et al., 2008 \\
\hline Matlab - AquaDyn & Evaluate bivalve grazing activity (Tracadie Bay) & Offline & Grant et al., 2008 \\
\hline ELCOM / CAEDYM & $\begin{array}{l}\text { Elucidate temporal and spatial variability of food } \\
\text { supply to clams (Barbamarco Lagoon) }\end{array}$ & Offline & Spillman et al., 2008 \\
\hline
\end{tabular}

GEMMS (Generalized Environmental Modelling System for Surfacewaters), ROMS (Regional Ocean Modelling System), ELCOM (Estuary and Lake Computer Model), CAEDYM (Computational Aquatic Ecosystem Dynamic Model), EcoDynamo (Ecological Dynamic Model). 